\title{
AN EVALUATION OF ITS NATURAL HISTORY AND THE EFFECTS OF THERAPY, WITH PARTICULAR REFERENCE TO TREATMENT BY MASSIVE DOSES OF VITAMIN $B_{12}$
}

\author{
BY \\ MARTIN BODIAN* \\ From The Hospital for Sick Children, Great Ormond Street, London
}

(RECEIVED FOR PUBLICATION MAY 13, 1963)

The problem of cancer in childhood assumes increasing importance as other formerly killing diseases, notably infections, have been to a large extent conquered. In recent years malignant neoplastic disease has accounted for 15 to $20 \%$ of deaths from natural causes in children between the ages of 1 to 14 years in England and Wales, and similar figures have been obtained from other countries, including the U.S.A. and France.

Tumours arising from the sympathetic nervous system, i.e. neuroblastoma, ganglioneuroma and phaeochromocytoma, accounted for roughly $10 \%$ of neoplasms seen at The Hospital for Sick Children during the period from 1925 to 1962 inclusive. The other major figures were about $36 \%$ leukaemia, $25 \%$ intracranial neoplasms and $7.5 \%$ nephroblastoma. The total number involved during the quoted period was about 1,800 .

The following remarks in this paper will be entirely concerned with sympathetic nervous system tumours, and in particular with neuroblastoma. In the period from 1925-1962 inclusive the number of verified cases of neuroblastoma was 165 , that of ganglioneuroma, 18 and of phaeochromocytoma, one.

\section{Age and Sex Incidence}

The great majority (133) of affected children presented with symptoms during the first four years of life, and the first year of life (infancy) accounted for 63. The sex distribution was about equal; 79 male $(47 \cdot 9 \%), 86$ female $(52 \cdot 1 \%)$.

\section{Sites of Origin}

It is known that neuroblastoma may arise either in the adrenal medulla or anywhere in the sympathetic nervous system. Thus we have encountered an origin from the adrenal gland or from the upper

\footnotetext{
* Dr. Bodian died on September 25, 1963.
}

abdominal sympathetic chain in more than twothirds of the cases $(68 \%)$. Cervical tumours were found in seven cases, thoracic tumours in 20 cases and pelvic tumours in 13 cases. In one notable instance four apparently independent growths were found arising in the thorax, adrenal, upper abdomen and pelvis. In 12 instances the site of the primary growth could not be definitely ascertained.

\section{Pathology}

Neuroblastoma has certain features that tend to distinguish it from any other type of tumour, and that bear an important relation to its secondary manifestations.

1. The tumours tend to be highly invasive and to infiltrate surrounding tissues readily. Not uncommonly they surround major vessels and render complete surgical removal impossible. One of the striking features is the rapidity with which such tumours extend and metastasize, mainly by lymphatic and haematogenous dissemination. The mode of spread is: (a) to lymph nodes, both local and/or distant; (b) to the liver; (c) to the skeleton; (d) epidural extension. Any other organ may also be involved but the most common forms of dissemination are the ones already recorded. Dissemination to the skeleton is extremely common except in the first year of life. It will be seen from remarks later on that this has an important bearing on the prognosis of this condition in the first year of life and thereafter. Dissemination to the liver is particularly common in the first year of life, and it has been suggested that Pepper's syndrome occurs more commonly from right-sided adrenal neoplasms than from left-sided tumours. This has been confirmed in our own series, and is entirely due to the more common lymphatic extension from right-sided tumours to the liver. Haematogenous dissemina- 
tion, on the other hand, is equal from both sides. Similarly, haematogenous dissemination to the skeleton is also equal from both sides and the alleged prominence of left-sided tumours in Hutchinson's syndrome has not been confirmed. In common with others we have observed that tumours arising from the adrenal glands or from the extra-adrenal abdominal region have the highest tendency to disseminate, whereas other extra-adrenal tumours (cervical, thoracic and pelvic) do not show such a high degree of dissemination, and the pelvic tumours in particular show a relatively low incidence of extension.

2. The neuroblastic tumour has a marked tendency to undergo necrosis, which sometimes is of such an extent that only few viable areas remain. Unfortunately complete extinction of neoplastic tissue is exceedingly rare although well authenticated, and completely spontaneous regression accounts for not more than about $1 \%$ of all the cases seen. We ourselves have only observed one instance in our series, and only one instance has been recorded in more than 200 cases of neuroblastoma at the Cancer Memorial Hospital (H. W. Dargeon, personal communication).

3. In common with other embryonic tumours neuroblastoma has a tendency to differentiate, and many cases show such evidence with, side-by-side, areas of primitive neuroblastic tissue and areas in various stages of differentiation, even as far as fully mature ganglioneuroma. We have encountered such gradation of differentiation in many cases, and wellcircumscribed ganglioneuromatous masses were found enveloped by neuroblastic tissue. It is therefore clear that serial biopsies (obviously derived from different portions of the tumour) cannot be adduced as evidence of progressive differentiation due to one or other form of treatment.

\section{Clinical Manifestations}

The remarks on the pathology expressed in the previous section are clearly borne out in the clinical manifestations of this condition, but it is important to realize that two-thirds of the children in the present series when first seen by a doctor already showed clinical evidence of dissemination, while the symptoms due to the primary tumour might not be so obvious.

Constitutional disturbances were a frequent presenting feature, including fever, anaemia, vomiting, malaise, and they could probably be related to the considerable degree of necrosis in many of these tumours. Not uncommonly such symptoms are interpreted in the initial stages as indicating infection.
Paralysis of the sympathetic nervous system can produce presenting symptoms such as occur in Horner's syndrome in tumours of the cervical and upper thoracic regions, and sometimes simulating coeliac disease in tumours arising from the abdominal sympathetic system. Presentation with signs of spinal cord compression may occur owing to the dumb-bell configuration of some tumours, a portion being situated in the extradural space of the spinal canal.

Exceptionally neuroblastoma is discovered accidentally on routine post-mortem examination, and we have ourselves encountered four such examples. In one interesting instance the presentation was with hypertensive encephalopathy, and a neuroblastoma arising from the adrenal gland was found at autopsy.

\section{A Series of Untreated Cases of Neuroblastoma}

It has already been pointed out that neuroblastoma is a condition that shows a remarkable tendency to disseminate widely at a very early stage of its evolution. From a therapeutic point of view it is therefore clear that a hopeless attitude by clinicians was justifiable in the recent past, and this has been the attitude taken in this hospital. Thus we have collected a series of 58 children in whom no active treatment was undertaken, but it should be stressed that all these cases have been histologically confirmed, either by means of biopsy or at autopsy. The average survival period of the untreated fatal cases was four months from symptomatic onset. The distribution of primary sites of origin and metastases was representative of the general series. Among the 58 children included, no less than 20 showed a symptomatic onset of the illness in the first year of life, and 19 of these succumbed to the disease, as did all the ones aged more than 1 year. In all, 57 of the 58 children have succumbed; only one of these survived 14 months; all the others succumbed within one year of symptomatic onset of the disease, the average being four months. The one solitary survivor is the only instance of spontaneous regression in our series: a 4-month-old boy presented in 1947 with a mass in the chest, a grossly enlarged liver, and a subcutaneous nodule which proved histologically to be a deposit of neuroblastoma. In the absence of any form of treatment this child is alive and in good health at present (aged 15 years), the only clinical abnormality being residual calcification on radiographs in liver and thorax. Presumably the primary site of the tumour was in the chest.

If there is a biological advantage in favour of 
the first year of life in neuroblastoma, this has certainly not manifested itself clinically in the series of untreated children.

\section{A Series of Cases of Neuroblastoma Submitted to Operation and/or Radiotherapy}

This series included a total of 25 children treated by operation, radiotherapy, or a combination of both. This group was highly selected in that preference was given to children with no, or limited, evidence of dissemination, to children in the younger age-group, and to children with extra-adrenal origin of the tumour.

Of the 25 children, 17 succumbed within six and a half months of symptomatic onset, and eight patients have been long-term survivors for periods varying from three years to 25 years. It will be seen that four of the eight surviving children had a pelvic primary tumour (the site with the best prognosis), and that secondary spread was found in one solitary instance only. This patient was admitted to hospital in 1933 at the age of 4 years and 10 months with an axillary tumour. The mass was excised and radium applied superficially. The growth had originally been diagnosed as a lymphosarcoma, but re-examination by the author leaves no doubt that it was a metastasis, in a lymph node, of neuroblastoma. At the age of 26 this patient was re-examined with no radiological evidence of any calcification in chest or abdomen, and with no clinical abnormalities whatsoever. Clinically the site of the original primary tumour remains unknown, and it must be assumed that the primary growth has regressed spontaneously. The lymph node metastasis has not recurred.

As stated before, surgical treatment and radiotherapy, both being essentially localized forms of treatment, are not entirely suited to the problem of cure in neuroblastoma. It should be noted that nine of the children in this group of 25 showed a symptomatic onset of the disease within the first year of life, and five of them fell into the group of eight long-term survivors, whereas four succumbed as did 13 others in the older age-group. The majority of cases showed widespread dissemination of tumour, and thus it seems likely that the therapeutic solution must lie in the discovery of a suitable effective chemotherapeutic agent.

\section{Neuroblastoma Cases Treated with Massive Doses of Vitamin $B_{12}$ with or without Addition of Surgery and/or Radiotherapy}

In November 1950, a new form of treatment was introduced into the therapeutic armamentarium of neuroblastoma at this hospital. Massive concen- trates of vitamin $B_{12}$ were made available at that time by the generosity of the Squibb Company, and the then Tumour Committee of the hospital (composed of Mr. G. H. Macnab, Professor A. Moncrieff, and the author) decided that it should be used on patients with neuroblastoma. The reasoning behind this decision was that since vitamin $\mathbf{B}_{12}$ was an essential factor for the normal maturation of haemopoietic cells, it might possibly enhance the maturation of neuroblastic tissue towards ganglioneuroma. A completely unselected series of cases of histologically proved neuroblastoma was given this treatment, either solely or in addition to operation and/or radiotherapy. The dosage was $1 \mathrm{mg}$. $(1,000 \mu$ g.) intramuscularly on alternate days for at least two years whenever survival permitted, and this was increased from 1957 onwards to $1 \mathrm{mg}$. per $7 \mathrm{~kg}$. (1 stone) of body weight, and the duration of treatment was also increased to three years. The dose was clearly empirical; the duration of treatment, however, was based on the observation that recurrence of this tumour after more than three years is quite exceptional.

Reference will now be made to brief clinical summaries of all the cases treated, and they will be grouped into (a) those with remission of tumour, most of whom are alive except two who have succumbed to intercurrent disease, (b) those fatal, with temporary remission of tumour, and (c) those who failed to respond clinically.

\section{Group I: With Clinical Remission of Tumour}

Case 1. Male, born April 10, 1950, admitted to this hospital aged 7 months with retention of urine of recent onset. After decompression of distended bladder by suprapubic cystotomy, a large fixed presacral mass was palpable extending around rectum, almost filling pelvis and projecting upwards into left iliac fossa. Biopsy through rectal wall on two occasions showed neuroblastoma with minimal differentiation.

His general condition was poor and there was persistent urinary infection. Surgical excision of massive tumour seemed out of question. Expert opinion considered radiotherapy unlikely to be successful. Metastases not found. It was decided to give him $1 \mathrm{mg}$. vitamin $\mathbf{B}_{12} \mathrm{i} . \mathrm{m}$. on alternate days. After four months' treatment tumour no longer palpable through abdominal wall, but there was some infiltration in vicinity of prostate on rectal examination. Subsequently urine was voided per urethram and suprapubic tube was removed.

After 15 months' treatment laparotomy was performed in hope of obtaining residual ganglioneuroma. Only remnants of tumour were two minute retroperitoneal nodules on left of sacrum, that were palpable but not visible. Treatment was maintained for two years. Child now in good health and free from recurrence or metastases, 12 years after clinical onset of disease. 
Case 2. Female. Born December 27, 1950, and admitted aged 9 months. There had been absence of sweating of left side of face for two months and drooping of left eyelid for one month.

On examination spastic paraplegia of legs was found, as well as left Horner's syndrome; enlarged lymph nodes in left cervical, supraclavicular and axillary regions, and upper left zone of chest was full and dull to percussion. Radiograph revealed large mass in left upper mediastinum displacing oesophagus downwards and to right. There was erosion of necks of ribs in region of mass, and intervertebral foramina were enlarged. A supraclavicular lymph node biopsy revealed primitive neuroblastic tissue. Radiotherapy was given to chest tumour for 10 days, total dosage $875 \mathrm{rad}$. No change in size of tumour was seen; the radiotherapist considered tumour insensitive to treatment, and abandoned it. Vitamin $B_{12} 1 \mathrm{mg}$. i.m. on alternate days was commenced and continued for two and a half years to March 1955. By January 1953 there was considerable diminution in size of chest tumour, and in size of lymph nodes in neck and axilla. Paraplegia and Horner's syndrome persisted. Thereafter there was gradual improvement in limb movements, and in June 1953 only trivial neurological abnormalities remained. Horner's syndrome, however, persisted. No evidence of spinal block obtained on lumbar puncture. She began to walk unaided. Chest radiograph showed complete disappearance of tumour. Lymph nodes disappeared and few tiny calcified nodes palpable beneath skin. Child now perfectly well, more than 11 years from symptomatic onset of disease. Left iris slightly less pigmented than right and there is slight permanent residue of Horner's syndrome.

Case 3. Female. Born October 15, 1953, was admitted to hospital in Sweden aged 5 months because of episodic Horner's syndrome and vasomotor disturbances of right eyelid from age of 1 month. A cervical mass was palpated and small 'gland' typical of neuroblastoma excised from this region. Radiotherapy in small doses (400 rad) administered and produced transient remission of symptoms. Cervical mass recurred and vitamin $B_{12}$ was begun at 11 months at this hospital, and continued for two and a half years. Tumour regressed and child is now alive and well, more than 9 years old and 9 years after symptomatic onset of illness. She has returned to Sweden.

Case 4. Female. Born February 15, 1953, admitted at 10 months because of paralysis of legs since birth with evidence of sphincter paralysis. Laminectomy was performed. Extradural tumour found which was partially removed, and which contained both neuroblastoma and neurofibroma. Laparotomy revealed small paravertebral tumour which was excised and which showed a similar histological structure. Vitamin $\mathbf{B}_{12}$ therapy instituted and child was known to be alive and well two years and three months after commencement of treatment, when she was lost sight of. (She had emigrated to Canada and could not be traced.)
Case 5. Female, presented at 4 months with weakness of both lower limbs, especially of left. Double sphincter weakness was suspected. At 9 months child was admitted to Beilinson Hospital, Israel (May 3, 1954). In left lumbar region at level of L2-3 a hard mass was palpable 'the size of an orange'. There seemed to be complete anaesthesia from L1 downwards, flaccid paralysis of right leg and almost complete paralysis of left lower limb. Radiograph showed round, calcified paravertebral mass to left of upper lumbar spine. Myelography revealed filling defect on left side of spinal canal in upper lumbar region. Laparotomy, June 8, 1954, revealed left-sided retroperitoneal tumour infiltrating muscle and extending into spinal canal through intervertebral foramina. The tumour 'the size of an egg' was considered inoperable, and only a biopsy specimen was obtained, which was examined by author and proved to be neuroblastoma with some areas showing moderate degree of differentiation. There was infiltration of adjacent skeletal muscle and necrosis and calcification. On July 7, 1954, she was admitted with gross paralysis of both lower limbs, especially the right, and sensory loss over whole of right lower limb. Spinal cord and membranes were displaced to right from L1-L5. Laminectomy from L2-L5 and dura found to be completely covered by purplish-grey firm tumour. Only a biopsy was removed and microscopy showed neuroblastoma with some calcification. Vitamin $B_{12}(1 \mathrm{mg}$. i.m. on alternate days) initiated on July 16, 1954. At end of September 1954, child returned to Israel with improvement in power of lower limbs. There was still incontinence. Her general health was excellent. Vitamin $B_{12}$ was continued, and at end of June 1955 she was brought back here. Her condition was excellent; she had good weight increase; abdomen was not distended; tone of lower extremities still diminished, particularly on left; moderate power, better on left than right; reflexes absent; she walked on wide base using surgical boots. On skeletal survey there were no metastases. She returned to Israel in September 1955. Voluntary movement of both lower limbs had improved and tone was nearly normal. Vitamin $B_{12}$ was continued and she progressed very well.

In June 1957, however, she contracted bulbar form of poliomyelitis, nearly at the end of a two years' course of vitamin $\mathbf{B}_{12}$. She succumbed within 30 hours of admission to hospital. At autopsy only a fibrous scar was found at site of former tumour, and complete regression was also established by exacting histological examination confirmed by author.

Case 6. Male. Diarrhoea since 1 year; thought elsewhere to have coeliac disease. Admitted to Great Ormond St. at 17 months as ? coeliac disease. Three weeks later abdominal mass palpated. At laparotomy tumour weighing $100 \mathrm{~g}$. was found between right ureter and inferior vena cava, and was removed together with adjacent enlarged lymph nodes. Microscopically tumour consisted of slightly differentiated neuroblastic tissue showing in parts ganglioneuromatous structure. Lymph nodes were invaded. A course of radiotherapy was given, 
and vitamin $\mathbf{B}_{12}, 1 \mathrm{mg}$. i.m. on alternate days, given for more than five years.

Child and parents have emigrated to Canada, but follow-up maintained, and he is alive and well without any recurrence of tumour, aged $9 \frac{1}{2}$ years, and eight and a half years after symptomatic onset of disease.

Case 7. Female, born September 21, 1953, admitted to hospital at 15 months of age because of inability to walk or crawl for three months. There was scoliosis and signs of spinal cord compression with wasting of lower limbs. Radiograph revealed large calcified mass to left of spinal column extending from T8 to L1 with partial destruction of adjacent ribs and vertebral transverse processes. Radiotherapy administered, but two months later paralysis increasing and myelography demonstrated large extradural tumour. Extensive laminectomy was performed at 18 months; large tumour found firmly adherent to dura, and biopsy showed viable primitive neuroblastic tissue in spite of previous radiotherapy. Vitamin $\mathbf{B}_{12}, 1 \mathrm{mg}$. i.m. on alternate days, was instituted and continued for two and a half years until June 1957.

She is alive now, aged more than 9 years, and eight years from symptomatic onset of disease. Abdominal tumour mass has regressed, although no radiotherapy was applied. There is persistent paraplegia of lower limbs. Bowel control is good; bladder control fairly good. She is able to walk with crutches.

Case 8. Female, born August 1, 1955, admitted here when 3 hours old with huge nodular abdominal mass on right side extending from costal margin to inguinal ligament, and across to left flank, fixed and apparently arising from loin and indistinguishable from liver. Mass was palpable per rectum. Her general condition was good. At laparotomy on August 3, 1955, mass identified as liver showing numerous nodular neoplastic deposits. Biopsy showed massive replacement of liver parenchyma by primitive neuroblastoma, as well as infiltration of portal lymphatics with tumour. Radiologically there was no evidence of metastases to skeleton or lungs. Vitamin $B_{12}, 1 \mathrm{mg}$. i.m., on alternate days was commenced, and continued for two and a half years as sole form of treatment. After transient increase in size of abdomen, mass was decreasing by October 1955 , and by February 1956 liver edge was barely palpable, and intravenous pyelogram was normal, without calcification in suprarenal regions.

She has made uninterrupted progress, and is perfectly well without evidence of recurrence of tumour at $7 \frac{1}{2}$ years. Urinary vanillyl-mandelic acid is now normal.

Case 9. Female, admitted at $1 \frac{1}{2}$ years of age with history of lump in right labium for six months which had been removed in South Africa and proved to be neuroblastoma deposit. Lump had recurred and enlarged slowly, and on examination there was small palpable lymph node in right axilla, some resistance in left upper abdomen, and intravenous pyelogram showed low left kidney. Skeletal survey showed no evidence of secondary deposits. On January 9, 1956, at age of 18 months, primary left suprarenal tumour was removed, weighing $39 \mathrm{~g}$. and consisting of fairly primitive neuroblastic tissue. Secondary deposits were removed from axillary lymph node and inguinal lymph node, and in vulva. Subsequently on June 18, 1956, further invaded lymph nodes were excised from both inguinal regions. Patient started on vitamin $B_{12}, 1 \mathrm{mg}$. i.m., and received this treatment for two and a half years. She is now alive and well without signs of recurrence aged $8 \frac{1}{2}$ years, and seven and a half years after symptomatic onset of illness.

Case 10. A boy, born February 10, 1954, was discovered to have intrathoracic mass when investigated for unexplained febrile episodes. Fairly complete excision of tumour was possible, which was found to be neuroblastoma. Post-operative radiotherapy was given, and vitamin $B_{12}, 1 \mathrm{mg}$. i.m. on alternate days, for two and a half years. There has been no recurrence of tumour, and he is now well at 9 years, nearly seven years from symptomatic onset of disease.

Case 11. Male. At birth, on May 14, 1956, he was noted to have extreme flaccidity of lower limbs and tumour was felt in right loin. At 3 weeks of age he was admitted here in satisfactory general condition. A large firm palpable mass obliterated right costolumbar angle. Radiographs of abdomen and spine revealed mass of calcification to right side of 2 nd and 3 rd lumbar vertebrae. Spinal canal appeared slightly widened and pedicles thinned with some suggestion of calcification within canal. There was some new bone formation along shaft of left femur. Biopsy of primitive neuroblastoma was performed by posterior retroperitoneal approach. Vitamin $B_{12}, 1 \mathrm{mg}$. i.m., every second day was given for three years as sole form of treatment. In March 1957 abdominal mass had become impalpable. There was still flaccid paraplegia of both legs, without sensation. Erosion of pedicles of vertebrae had disappeared and radiographs of long bones and skull were normal.

He is now alive aged 6 years and 7 months, without recurrence of abdominal tumour. There is no evidence of return of motor power to lower limbs, and he had uretero-ileostomy for recurrent urinary infection. His vanillyl-mandelic acid test in June 1962 was normal.

Case 12. Female, born August 26, 1954, had sacral tumour, noticed at birth. At 3 months biopsy reported as being chordoma, but sections were sent to author who considered this to be undifferentiated neuroblastoma. No treatment was given and child was referred to this hospital at 2 years with large mobile soft mass over sacrum. On rectal examination there was large nodular mass palpable in front of rectum and attached to rectal wall. Partial excision was performed and it was considered that at least half of mass remained in situ. Specimen weighed $93 \mathrm{~g}$. and consisted largely of mature ganglioneuroma, but showed residual areas of immature neuroblastoma. Vitamin $B_{12} 2 \mathrm{mg}$. i.m. on alternate 
days, was given for two years. Child is still alive and well now aged 8 years and 4 months, without recurrence of tumour and without symptoms, but with small palpable nodule on anterior surface of sacrum.

This case suggests largely spontaneous maturation of neuroblastoma to ganglioneuroma.

Case 13. Male, born February 26, 1955, admitted at 20 months with hard swelling on right side of neck for two months. Biopsy showed neuroblastoma. Primary tumour in right posterior mediastinum was excised together with many mediastinal lymph node metastases, and this was followed by block dissection of right cervical lymph nodes. After operation Horner's syndrome was noted. He had deep x-ray therapy to right cervicothoracic regions. Vitamin $B_{12}, 1 \mathrm{mg}$. i.m. on alternate days, was established, and continued for two and a half years. He has persistent Horner's syndrome but is free from recurrence of tumour, now aged 8 years, and six years after symptomatic onset of disease.

Case 14. Female, born February 21, 1957, admitted at 2 weeks of age with oedema for six days and retention of urine from 8 days. Bladder was enlarged above umbilicus, and large pelvic tumour was discovered which was only partially excised and found to be neuroblastoma. Treatment consisted of vitamin $B_{12}, 1 \mathrm{mg}$. i.m. on alternate days, for three years from March 1957 to March 1960. She had no radiotherapy. She died in July 1960 of acute intestinal obstruction due to adhesions following partial excision of neuroblastoma. At autopsy no residual tumour was found, either on gross examination or on microscopic examination.

In summary, this was a neonatal case of massive pelvic neuroblastoma, only partially excised and afterwards treated by vitamin $\mathbf{B}_{12}$ only for three years. Death was due to incidental intestinal obstruction at 3 years and 5 months, four months after completion of vitamin $\mathbf{B}_{\mathbf{1 2}}$ course. At autopsy no evidence of tumour residue found.

Case 15. Female, born September 17, 1949, and admitted at $8 \frac{1}{2}$ years with a six-month history of pain and swelling of right heel. Biopsy showed tumour, a secondary deposit of neuroblastoma in right astragalus. Primary tumour was not found, and in order to eliminate solitary secondary bone deposit, below knee amputation of right leg was performed in May 1958. Only other treatment carried out was vitamin $B_{12}$ therapy, $5 \mathrm{mg}$. i.m. on alternate days for three years. She is now well and free from recurrence, aged 13 years, and more than four and a half years after excision of secondary deposit, and more than five years from symptomatic onset of disease. She has been fitted with artificial limb.

Case 16. Male, born November 29, 1957, admitted aged 11 months with a month's history of being unwell, suffering from cough and from some stiffening of legs. Diagnosis of mediastinal tumour with cord involvement was made at an army hospital in Germany and child was referred to this hospital. Chest radiograph showed superior mediastinal mass posteriorly with erosion of the 4 th and 5th ribs projecting to left of midline. There was hypotonia with paralysis of lower extremities, with bilateral ankle clonus and brisk reflexes. Laminectomy carried out on October 30, 1958, and incomplete removal of extradural tumour achieved. Thus satisfactory cord decompression was obtained. He received radiotherapy to spine for five weeks (total dose 2,000 rad) with very little significant improvement in tone of lower limbs. On February 5, 1959, exploratory thoracotomy revealed several small ill-defined masses. Biopsy of one confirmed presence of neuroblastoma in fibrous tissue. During this time he was on vitamin $B_{12}, 1 \mathrm{mg}$. i.m. on alternate days, which was continued for three years. He is alive, aged 5 years, and more than four years from symptomatic onset of disease, but there is persistent paraplegia of lower limbs. There is no recurrence of tumour.

Case 17. Male, born June 19, and was admitted at 5 months of age without complaints, but parents said that routine chest radiograph had revealed mass in right chest. There was a large round mass lying posteriorly in right upper chest with some separation of posterior ends of 4th and 5th ribs. Skeletal survey normal. On December 2, 1958, at thoracotomy large firm encapsulated tumour approximately $10 \mathrm{~cm}$. in diameter was removed, but there were some deep extensions into intervertebral foramina, which were not excised. Histology was neuroblastoma. Post-operative x-ray therapy was given, total dose $1,735 \mathrm{rad}$, and also vitamin $B_{12}$ i.m., $1 \mathrm{mg}$. on alternate days, for three and a half years. He is now $4 \frac{1}{2}$ years and alive and well, without recurrence of tumour, more than four years after discovery.

Case 18. Female, born February 25, 1958, had been investigated at provincial hospital for posterior mediastinal shadow associated with fever and intermittent dysphagia; at 9 months right thoracotomy revealed large tumour which was removed; it had been fixed along paravertebral region and extended across midline into opposite side of mediastinum. Histology showed it to be neuroblastoma of high-grade malignancy. She was referred here and displayed flaccid paraplegia of lower limbs with both plantars extensor, and without any evidence of definite skeletal secondary deposits. It was decided not to proceed with decompressive laminectomy, but to start her on vitamin $\mathbf{B}_{12}$ treatment, $1 \mathrm{mg}$. i.m., on alternate days. At 2 years she had recurrence of thoracic tumour and paraplegia of limbs was unaltered. Tumour was excised by means of right thoracoabdominal approach, and she was given post-operative radiotherapy. Histological examination showed largely mature ganglioneuroma, but also minority islands of less differentiated cells. Vitamin $\mathbf{B}_{12}$ had been continued all the time in the same dosage. She subsequently presented with several recurrent attacks of urinary infection, which were treated with gantrisin. She had an intercurrent episode of ataxia of upper limbs and trunk, together with nystagmus which improved spontaneously and which was never adequately explained. Vitamin 
$B_{12}$ was continued for three years after removal of thoracic tumour without any further recurrence, and she is now well, with persistent paraplegia of limbs and scoliosis, aged nearly 5 years and more than four years after symptomatic onset of illness. Her vanillyl-mandelic acid level in 24-hour specimen of urine is normal. This case suggests maturation of neuroblastoma to ganglioneuroma.

Case 19. Female, born August 18, 1958. Enlarged abdomen noticed at 5 months, and at 7 months she was admitted to local hospital, and referred here at 8 months, where gross liver enlargement was found with slightly nodular firm surface. Right lobe extended to right iliac fossa. She was slightly wasted. Haemoglobin $69 \%$; platelets 33,000 per c.mm. Intravenous pyelogram (I.V.P.) showed downward and medial displacement of right kidney but normal calyces. Laparotomy on April 29, 1959, at 8 months revealed that mass was enlarged liver with mottled appearance due to secondary deposits. A biopsy showed diffuse replacement of liver tissue by neuroblastoma with intervening fibrosis. Vitamin $B_{12}, 1 \mathrm{mg}$., was instituted as sole form of therapy, and was given daily for first three months and on alternate days for remainder of three years. After four months some regression of liver was noticed, and this improvement continued progressively. One year after onset of treatment there was only slight liver enlargement and consistency felt fairly normal. After two and a half years liver was considered to be of normal size and consistency. At end of three years' course, and before ceasing treatment, I.V.P. was normal, there being slight calcification in region of left adrenal. At second laparotomy liver was of normal size, containing firm areas of whitish tissue, suggesting some scar formation, but otherwise grossly normal. In left adrenal area walnut-sized lump was felt but not seen. Two biopsies were taken, one from normal-appearing area and other from a whitish area. Normal-appearing area was histologically normal, and whitish area showed some scar formation as well as Schwann cells and few quite mature ganglion cells, but no neuroblasts. Vanillyl-mandelic acid level was normal; vitamin $\mathbf{B}_{12}$ was discontinued. She is now well with no signs of recurrence of tumour, aged 4 years 4 months, about four years after symptomatic onset of disease.

Case 20. Female. At about $8 \frac{1}{2}$ years, in December 1958, she was first seen with pain in left leg, tenderness over middle third of left tibia, and some redness but no swelling. There was some periosteal reaction and osteomyelitis was diagnosed; she was treated accordingly in Turkey. Two months later tibia was explored and biopsy report from Turkey was of osteomyelitis. A further two months later radiographs showed alarming periosteal reaction, and a neoplasm was considered. Six months after onset of symptoms, i.e. in June 1959, she was referred here. After exploratory operation, mid-thigh amputation of left leg was carried out, and diagnosis was solitary secondary deposit of neuroblastoma in left tibia. There was no radiological evidence of further deposits, and no evidence as to site of primary tumour. She was treated with vitamin $\mathbf{B}_{12}$ $5 \mathrm{mg}$. i.m. on alternate days as sole additional therapy. In January 1960, secondary deposit of neuroblastoma found in right frontal bone, which was excised and local radiotherapy given. A further three years of vitamin $B_{12}$ in same dosage was given, and is just concluded without any further recurrence of tumour or metastases. She is in excellent general condition and has been fitted with an artificial limb. She is now about $12 \frac{1}{2}$ years, four years after symptomatic onset and respectively three and three and a half years after resection of two secondary deposits.

Case 21. Female, born August 18, 1958, was admitted June 15,1959 , at 10 months for urinary retention over 48 hours, irritability and loss of appetite. After catheterization a mass was felt through rectum mainly in left iliac fossa. It was fixed posteriorly and had replaced rectum anteriorly. Blood urea was $44 \mathrm{mg}$./ $100 \mathrm{ml}$. Urine contained numerous organisms and an occasional white cell. Four days after admission laparotomy (June 19) revealed large tumour arising out of pelvis with several large lymph glands lying along left internal iliac vein. These and mass were removed and diagnosis of neuroblastoma was made histologically. After operation she had little control of bladder or rectum. Subsequently she had three weeks' course of radiotherapy, and vitamin $B_{12} 1.5 \mathrm{mg}$. i.m. on alternate days. At end of November 1960, she was thought to have massive recurrence. Vitamin $B_{12}$ treatment was continued, and when last seen on October 15, 1962, she was well. No growth was palpable, but she had no urinary control and bladder was distended. An ileal loop ureterostomy was performed.

Vitamin $B_{12}$ treatment has been continued for three and $\mathbf{a}$ half years.

Case 22. Male, born December 29, 1956, always strained when defaecating, and was admitted to hospital in Cardiff with acute retention of urine, on which occasion pelvic tumour found lying on left side, with considerable narrowing of lumen of rectum. At 3 months solid tumour was removed from that area, measuring $4 \times 2$ $\times 2$ in., which proved to be neuroblastoma with high degree of malignancy. Radiotherapy was not given, but child was put on vitamin $B_{12}, 1 \mathrm{mg}$. twice weekly. When parents moved to London he was referred here and is now aged 6 years and alive and well, without recurrence of tumour but with enuresis and needing rectal washouts from time to time.

Case 23. Female, born March 11, 1956, had left adrenal neuroblastoma excised in November 1957 in New Zealand, followed by post-operative x-ray therapy and by vitamin $B_{12}$ injections, $1 \mathrm{mg}$. i.m. three times weekly; this was continued for three years, the latter part under supervision of this hospital. She is now 6 years and 9 months and well, without recurrence of tumour, five years after symptomatic onset of disease.

Case 24. Female, born September 6, 1958, was admitted in June 1960, having history of excessive thirst 
and polyuria for three months. At a local hospital a mass was found on left side of abdomen together with blood pressure of $190 / 130 \mathrm{~mm}$. Hg, and I.V.P. had shown some dilatation of lower calyx of left kidney. On examination here blood pressure was confirmed as $190 / 130 \mathrm{~mm}$. $\mathrm{Hg}$; fundi showed spastic tortuous arteries but no exudates. On June 29, 1960, at laparotomy a biopsy of left suprarenal mass was taken and histology showed it to be neuroblastoma; left kidney was removed in attempt to lower hypertension. Post-operative blood pressure remained raised. Post-operative radiotherapy was given, and vitamin $B_{12} 2 \mathrm{mg}$. i.m. on alternate days was started. Follow-up showed normal blood pressure. There was intercurrent episode of urinary tract infection which was treated successfully. She has now been followed for two and a half years from beginning of treatment without clinical evidence of recurrence of tumour, and is still on vitamin $B_{12}$. She is now 4 years and 3 months.

Case 25. Male, born in October 1954, developed pneumonia at 3 years of age while abroad, and during investigation at the Children's Hospital in Athens a tumour was discovered. An attempt was made to remove it but it was thought to be too large and treatment was abandoned, but radiotherapy was given as well as German anti-tumour drug. He was admitted here and left thoracotomy was performed on June 30, 1960, i.e. two and a half years after previously attempted removal, and on this occasion a large mass weighing $367 \mathrm{~g}$. was removed but complete excision was impossible. Histological examination showed it to be largely differentiated ganglioneuroma, but containing numerous areas in which differentiation had not yet taken place. It was decided not to give more $x$-ray therapy, but child was put on to $4 \mathrm{mg}$. vitamin $B_{12}$ i.m. on alternate days, and has had this for two and a half years now with further six months to go. He is at present alive and well without further recurrence of tumour, aged more than 8 years.

Case 26. Male, born in August 1959, he had had recurrent attacks of bronchitis since 11 months of age, and on chest radiograph in Nicosia, a shadow in right lung was found at 14 months. He was referred to this hospital and on November 14, 1960, right thoracotomy revealed tumour occupying upper third of chest which was removed. Some tumour tissue had to be left behind and post-operative deep x-ray therapy was given. On histological examination tumour proved to be neuroblastoma, and there was evidence of infiltration of mediastinal lymph nodes. He was put on vitamin $\mathbf{B}_{12}$ in $1.5 \mathrm{mg}$. i.m. on alternate days, and two years of a three-year course have now been completed without recurrence of tumour.

Case 27. This female child was admitted at 4 years and 2 months always having had abdominal enlargement, but an increased hardness had been noted for past three months. On November 17, 1960, at laparotomy a large abdominal tumour was removed. Excision was probably incomplete as extension into intervertebral foramina was noted. Histology showed fairly mature ganglioneuroma with minority areas of less mature tissue, and vitamin $B_{12} 3 \mathrm{mg}$. i.m. was given on alternate days for one year. She is alive and well, aged 6 years now, without evidence of recurrence of tumour.

Case 28. Female, born February 19, 1961, was noticed immediately after birth to have flaccid paresis of lower limbs. C.S.F. from cisternal puncture showed protein, $100 \mathrm{mg} . / 100 \mathrm{ml}$., and on myelography complete block was found at level of D9. On February 25 a biopsy of extradural spinal tumour showed it to be neuroblastoma. Laminectomy had been carried out in order to relieve pressure only, but complete removal of tumour was considered impossible. No intra-abdominal tumour was palpable. At time of operation she was treated with vitamin $\mathrm{B}_{12}, 1 \mathrm{mg}$. i.m. on alternate days, and radiotherapy (total dose $750 \mathrm{rad}$ ) was applied to spinal cord extension of tumour. In September 1961 no abdominal mass was palpable, but bilateral paresis of lower limbs was unaltered. She developed purulent cervical adenitis in February 1962 and swelling was drained. In September 1962 she developed cellulitis of right knee but improved with penicillin. She has no evidence of recurrence of tumour now, aged 1 year and 10 months. She is constipated; she crawls; she stands up holding on, but does not attempt to walk.

Case 29. Female, born March 5, 1961, was admitted as emergency at 4 months. Two months before admission nodules had appeared in skin, which had increased in size and number. On examination 15-20 hard nodules were noted in skin on anterior abdominal wall, and hard mass was palpable on left side of abdomen. Liver was enlarged and nodular to palpation. One of skin nodules was excised and found to be neuroblastoma. On July 21, 1961, left adrenal neuroblastoma was removed together with kidney. Radiotherapy was given after operation, total dose $850 \mathrm{rad}$. She was also treated with vitamin $\mathbf{B}_{12}, 1 \mathrm{mg}$. i.m. on alternate days. Examination on January 28, 1963, in Cyprus showed healthy child of normal development. Liver was not palpable. Subcutaneous nodules on neck, abdomen and behind knees were still palpable. Chest and skull radiographs normal; blood count normal. Vitamin $\mathbf{B}_{12}$ continued in same dosage.

Case 30. Female, born February 14, had feeding problem in neonatal period. Radiograph showed gaseous distension; always constipated. From early September 1961 she was unable to pull herself up and stopped kicking her legs. On examination: flaccid paralysis of both legs more noticeable on left; brisk reflexes; plantars extensor; lumbar puncture: C.S.F. $1,000 \mathrm{mg} . / 100 \mathrm{ml}$. protein with no white cells. Radiographs showed tumour of left mediastinum with rib erosion. She was admitted to this hospital on September 13, 1961, and showed dumb-bell type of tumour of dorsal spine and posterior mediastinum, with spinal compression. September 14: laminectomy from D5D10; fleshy tumour compressing thoracic cord; extension 
alongside intercostal nerve at level of D8-D9 on left side. Extradural tumour was totally removed. September 28: left thoracic excision of neuroblastoma adherent to chest wall and posterior mediastinum; both specimens composed of primitive neuroblastoma. Deep x-ray therapy given and vitamin $B_{12}, 1,000 \mu \mathrm{g}$., on alternate days. She is alive and apparently free of tumour, aged 1 year and 10 months.

Case 31. Male, born February 14, 1962, admitted on July 4, 1962, because of middle-ear infection; chest radiograph revealed mass in posterior mediastinum. On July 23 left thoracotomy was performed and neuroblastoma showing in some areas some differentiation was excised. $X$-ray therapy $(1,200 \mathrm{rad})$ given, and vitamin $\mathrm{B}_{12}, 1 \mathrm{mg}$. on alternate days. Excision in chest had been almost complete.

Case 32. Female, born May 15, 1961, because of umbilical hernia had been taken to family doctor who felt abdominal mass. Examination under anaesthesia on September 3, 1961, showed large mass at level of umbilicus extending into both sides of abdomen. I.V.P. showed lower poles of both kidneys displaced outwards, suggesting retroperitoneal tumour. Haemoglobin $61 \%$. September 11, 1961: laparotomy revealed large multiloculated mass situated retroperitoneally extending from upper abdomen into pelvic brim, which could not be freed. Biopsy taken which proved to be neuroblastoma. She was put on vitamin $B_{12}, 2$ mg. i.m. alternate days, and no radiotherapy given. Skeletal radiographs did not reveal any metastases. Methoxy-hydroxy-mandelic acid in urine $15 \mathrm{mg}$./24 hours. She was also given iron therapy for anaemia. When last seen on December 15 she was well, had a good appetite, and abdominal mass was unchanged.

\section{Group II: Fatal Cases With Temporary Remission}

Case 1. Male, born April 16, 1951, was first admitted on July 28, 1962, with cervical adenitis four months previously and orbital metastases from primary neuroblastoma almost certainly of left adrenal: proved by histological examination of subcutaneous metastasis to be neuroblastoma. There was severe anaemia, and enlarged cervical lymph nodes probably also contained tumour deposits. Course of palliative radiotherapy to skull was given without obvious benefit. He was put on vitamin $B_{12}, 1 \mathrm{mg}$. i.m., on alternate days from October 1952, with regression of skull metastases and marked improvement in general health. Anaemia had disappeared 14 months after admission to hospital. In November 1952 at $3 \frac{1}{2}$ years and 26 months after clinical onset of disease, further cervical metastases appeared. Mass was irradiated with $1,000 \mathrm{rad}$, but subsequently there was evidence of recrudescence elsewhere, and child died with widespread dissemination of metastases 32 months after onset of symptoms.

Case 2. Male, born September 24, 1952, and admitted to hospital at 3 months with massive enlargement of liver which was found to be result of extensive replacement by neuroblastoma tissue. Primary tumour was in upper abdominal region. He was given vitamin $B_{12}$, $1 \mathrm{mg}$. i.m., on alternate days as sole treatment for eight months. There was progressive reduction in size of liver and maintenance of excellent general condition. At second laparotomy eight months after admission liver was normal apart from solitary encapsulated metastasis which was excised and found to be primitive neuroblastoma as on first exploration, and now retroperitoneal primary tumour was seen; irradiation was undertaken without reduction in size and with apparent precipitation of metastatic spread. Death occurred at 14 months. At autopsy tumour was found in both adrenals, there was massive invasion of intestine, multiple secondaries in liver and chest, and large orbital metastasis. Nevertheless, there had been in this case striking and progressive regression of diffuse hepatic metastatic growth during administration of vitamin $\mathbf{B}_{\mathbf{1 2}}$.

Case 3. Female, born December 27, 1953, came under observation at 1 year with symptomless upper abdominal primary tumour which was removed surgically, together with adjacent invaded lymph nodes, many of which had to be left behind. Examination of bone marrow revealed cells suggestive of neuroblastoma, and diagnosis was histologically established by examination of tumour. Post-operative vitamin $\mathbf{B}_{\mathbf{1 2}}$ therapy, $1 \mathrm{mg}$. i.m., on alternate days, was given, but there was gross deterioration during next four months, with progressive anaemia and multiple skeletal metastases. Subsequently, however, there was gradual improvement with reduction in size of metastases, and haemoglobin was maintained. A year from presentation she was in good general health, but bony changes were still seen. However, she developed further metastases and died 18 months after onset of symptoms.

Case 4. Female, born February 9, 1953, presented at 10 months with jaundice and was found to have massive inoperable retroperitoneal tumour. Cholecyst-jejunostomy was undertaken and biopsy showed that growth was neuroblastoma. Subsequently she suffered recurrent jaundice and was admitted to this hospital three months after operation. There was slight anaemia but no radiological evidence of skeletal metastases. Vitamin $B_{12}, 1 \mathrm{mg}$. i.m., on alternate days was given, and for next eight months she was in good general health and free from jaundice and abdominal tumour appeared to be considerably smaller in size. However, there was dissemination of metastases and she died 21 months after onset of symptoms.

Case 5. Male, born February 7,1951 , at $5 \frac{1}{2}$ years presented with one month's history of abdominal pain and difficulty in micturition, followed by incontinence and flaccid paralysis of lower limbs. He was found to have erosion of 5th dorsal vertebra and complete spinal block at that level. As much of extradural tumour as possible was removed from D5-D7, which proved to be neuroblastoma. He was treated with vitamin $B_{12}, 2 \mathrm{mg}$. 
i.m., on alternate days, and given deep x-ray therapy to spine. There was no surgical exploration to discover primary tumour. He suffered from recurrent urinary infection, was well but incontinent and paralysed in lower limbs, 19 months after symptomatic onset. He died on January 9, 1959, having gradually deteriorated and ultimately disseminated. There was no autopsy.

Case 6. Female, born April 27, 1956, admitted at 1 year with enlargement of right side of abdomen for two months. She was found to have massive right-sided abdominal neuroblastoma infiltrating para-aortic lymph nodes and right ureter, thus producing hydronephrosis of right kidney. There was calcification in upper femoral epiphyses with periosteal thickening over femoral shafts, and primitive cells were seen in bone marrow smear. Lymph node biopsy established diagnosis of neuroblastoma and hydronephrotic right kidney was removed. Total tumour dose of $1,50 \mathrm{C}$ rad was given, as well as vitamin $B_{12}, 2 \mathrm{mg}$. on alternate days. She remained well for one year when she was readmitted with mass in left flank and marked uraemia. Ureteric catheterization was required and she improved temporarily. She was readmitted in March 1959 with large left-sided abdominal mass, uraemia, anaemia and right proptosis. Further $\mathrm{x}$-ray therapy was given with some relief, but general condition deteriorated and she died on May 7, 1959. Autopsy confirmed diagnosis and revealed multiple secondary deposits in lymph nodes, liver and bones.

Case 7. Male, born June 3, 1957, was admitted first on January 6, 1958, with upper respiratory infection for about four to five weeks. During latter part of illness family doctor palpated abdomen and noticed mass in left loin. I.V.P. was normal. On January 8, at laparotomy mass was identified as neuroblastoma attached to left kidney. Tumour, together with kidney, was excised as well as one or two small glands in the area. He was started on vitamin $B_{12}, 1 \mathrm{mg}$. i.m., on alternate days. He had radiotherapy and was noticed to have proptosis of right eye in March 1958 due to metastases. He was given local radiotherapy and was subsequently well, with no further recurrence of tumour until August 1959, when he developed swelling in right groin, found to be inflammatory, which resolved after chemotherapy. In December 1959 he showed multiple metastases of skull and marked anaemia, and he died on February 28, 1960. There was no autopsy.

Case 8. Male, born January 20, 1955. A small swelling was noticed in October 1956 near right nipple. Biopsy at provincial hospital showed neuroblastoma; no primary tumour found. Vitamin $\mathbf{B}_{12}$ was commenced, $1 \mathrm{mg}$. i.v. three times weekly, and a course of deep $\mathrm{x}$-ray therapy. His condition improved considerably, but in February 1958 a rapidly growing nodule was found again on chest wall. Radiograph of skeleton showed no metastases. He was admitted to this hospital and vitamin $B_{12}$ was increased to $2.5 \mathrm{mg}$. i.m. on alternate days. Intravenous pyelogram showed no abnormality of renal structures. By November 1958 there was marked growth of tumour mass in right chest, but he was still asymptomatic. On November 25, 1958, radical block dissection of tumour involving 4th right intercostal space was performed, and 4th and 5 th ribs were totally excised. Anterior segment of right middle lobe was resected, and also anterior segment of upper lobe. During removal of tumour there was spillage of necrotic pieces into chest. Pathological report on tumour was neuroblastoma, without neoplastic infiltration of lung segments or of hilar lymph nodes. X-ray therapy was not given, and he was continued on $B_{12}$. He was very well until May 1961, when the mother noticed another swelling on right chest wall and he became listless. He also complained of cough and pain in right chest. On July 20, 1961, an upper abdominal incision was made and extended across midline and sternum split. Liver was pushed down by mass of growth entirely replacing centre of diaphragm and involving lower mediastinum. During resection of growth massive haemorrhage occurred from central necrotic area of growth. Bleeding could not be controlled and heart stopped. At autopsy massive recurrence of right thoracic neuroblastoma was confirmed. The tumour had been partially excised and there was fatal haemorrhage from necrotic area of tumour; acute cerebral oedema had supervened.

\section{One Case Treated with Vitamin $B_{12}$ : Follow-up too Short}

R.K. Female, born July 17, 1962, was referred from the U.S. Air Force Hospital in Suffolk at 4 months with progressive abdominal enlargement in last month; also showed asymmetrical skull, webbed short neck, hypoplastic mandible and multiple skeletal congenital abnormalities (? glycogen storage disease). Needle liver biopsy on November 30 produced evidence of disseminated neuroblastoma. Skull radiograph showed osteolytic lesion of right maxilla involving floor of orbit and probably extending into right nasal fossa. Urinary vanillyl-mandelic acid, $41 \mathrm{mg} . / 24$ hours. Vitamin $B_{12}$ $1 \mathrm{mg}$. i.m. every second day was started December 1 , 1962.

\section{Group III: Clinical Failures}

There were 33 children in this group. It should be observed that frequently these children were at an advanced stage of the disease at the time when treatment was started, and that not uncommonly the rapid course precluded therapy beyond a relatively short duration. All but two of the children had shown clinical evidence of metastatic spread before vitamin $\mathbf{B}_{12}$ was started. The age of symptomatic onset varied from 2 years to 12 years and 9 months, and in two of the children onset occurred during infancy (respectively at 3 and 6 months). The average age of onset was 3 years and 11 months.

The adrenal was the primary site in 13 cases; the extra-adrenal region or adrenal in nine cases; 
there was one case with primary cervical tumour; there were three thoracic and two pelvic tumours, and four cases were of uncertain primary origin.

In 14 instances either no treatment was given other than vitamin $\mathrm{B}_{12}$, or else there was merelypalliative additional radiotherapy.

In all children coming to autopsy there were widespread metastases.

Although there was no appreciable evidence of clinical response to vitamin $B_{12}$ treatment in these 33 children, evaluation of survival figures reveals an average of 10 months compared with four months for untreated fatal cases, and with six and a half months for fatal cases treated by conventional methods.

\section{Conclusions}

Of 165 cases of neuroblastoma under consideration, 58 have been untreated (all but one with fatal issue); 25 children have received conventional forms of treatment, with eight surviving; 33 children having received vitamin $B_{12}$ for more than four weeks with or without conventional treatment have been complete clinical failures; eight children have shown temporary clinical benefit. Eight more recent children have been excluded; six of these have succumbed after less than three weeks $B_{12}$ therapy, and two have succumbed after a short interval without any $\mathbf{B}_{12}$ treatment. One child is of too recent date to be evaluated.

Finally there are 32 children who have been classified as clinical remissions; 30 of these are alive, 28 for periods of from more than two years to 12 years; two for one to two years. Two children have succumbed after $B_{12}$ treatment from intercurrent causes, with no evidence of residual tumour at autopsy.

The author realizes that it is difficult to apply strict statistical criteria to this series for the following reasons:

(1) It would have been impossible for humanitarian reasons strictly to alternate cases with and without vitamin $\mathbf{B}_{12}$ therapy, especially in the agegroup in which this treatment is most promising.

(2) The series of 58 untreated cases, though most impressive in its, alas, fatal results, precedes the vitamin $B_{12}$ treated series and also the purely surgically and/or radiotherapeutically treated children by many years and is, therefore, not strictly statistically comparable.

Nevertheless, there are too many cases recorded from this hospital and from outside sources (see the relative chapter), who have been treated solely with vitamin $B_{12}$ with great success for it to be denied that this substance has a significant influence on the growth rate of neuroblastoma. This clinical obser- vation is substantially supported by experimental work which is discussed in a later chapter and which has been published elsewhere. (See Bibliography.)

There is no doubt that the first 18 months of life carry by far the best prognosis in the vitamin $B_{12}$ treated series, but this advantage of the younger age-group was not manifest in the untreated series. It is also clear that the presence of bone metastases carries a bad prognosis: other metastases can be favourably influenced by therapy.

\section{Miscellaneous Infants with Neuroblastoma Treated Outside Great Ormond St. with Vitamin $\mathbf{B}_{12}$}

Among the many cases of neuroblastoma treated with vitamin $B_{12}$ in various parts of the world $I$ have chosen some infants in whom vitamin $B_{12}$ seems to have exerted a favourable response. The clinicians in charge of these infants have kindly given me permission to refer to their patients, for which I would like to express my deepest thanks.

Case 1. Baby L.Ch., male, born June 14, 1962, at full term, under the care of Dr. Lightwood and Dr. T. Oppé at St. Mary's Hospital, London, was second child of a healthy mother. Normal delivery; birth weight $7 \mathrm{lb} .10 \mathrm{oz}$. $(3,458 \mathrm{~g}$.). Seen on second day of life, found to be pale with distended abdomen and enlarged firm liver; spleen not felt; slight oedema of lower abdomen and legs; haemoglobin $14.5 \mathrm{~g}$. $/ 100 \mathrm{ml}$.; white blood cells 2,500 . Over next few days liver progressively enlarged until it reached right lower quadrant. Weight and pallor increased. I.V.P. showed normal calyces and possible slight downward displacement of right kidney.

On June 27 laparotomy revealed enlarged liver with multiple small nodules, white and stony hard, chiefly on undersurface of right lobe but also in left lobe. No disease found in either kidney. Small biopsy was taken from nodule in right lobe, which showed primitive neuroblastoma. Skeletal radiograph showed no abnormality. Consultant radiotherapist did not consider irradiation advisable, and baby was treated (and is still being treated) with $1 \mathrm{mg}$. vitamin $B_{12}$ on alternate days from June 29,1962 , increased to $1 \mathrm{mg}$. daily on July 3 . (Total duration of treatment, so far, one year.) For a time his condition remained poor and increasing abdominal distension caused moderate respiratory embarrassment. Bone marrow biopsy from tibia on July 6 showed no abnormal cells. Haemoglobin tended to fall and he required three small blood transfusions, the first at time of operation.

24-hour urine collections were assayed for vanillylmandelic acid both at The Hospital for Sick Children (21 mg. in 24 hours) and at Queen Charlotte's Hospital by Dr. Chandler (17.4 mg. in 24 hours, and homovanillic acid $9.4 \mathrm{mg}$. in 24 hours).

On August 13 distension and oedema slightly decreased, and he was considered fit enough to be sent home, vitamin $B_{12}$ being continued in same dose. 
Since discharge he has done well; haemoglobin levels were 11-12 g., abdominal distension and oedema slowly disappeared, and liver slowly decreased in size. Latter finding was first noted on August 29 (two months after beginning of vitamin $\mathbf{B}_{12}$ therapy) when it measured only 3 in. $(7.6 \mathrm{~cm}$.) below right costal margin, and when also there was noticed for first time difference in size of right and left arms. He continued to improve until he presented the picture of a normal healthy baby. Liver was less than 2 in. $(5 \mathrm{~cm}$.) below right costal margin.

Further urine collections have shown progressive fall in V.M.A. and H.V.A. excretion. On August 16 and 17, V.M.A. was $6.5 \mathrm{mg}$. in 24 hours and H.V.A. $7.5 \mathrm{mg}$. (Dr. Sandler). Urine collected on September 25 and 26 showed V.M.A. $1.9 \mathrm{mg}$. in 24 hours and H.V.A. approximately $0.045 \mathrm{mg}$. (Dr. Sandler).

Bilateral inguinal herniotomy on October 6 revealed smooth much smaller liver (except for few small nodules) which was palpated through herniotomy. Right kidney was normal, but right suprarenal gland was not palpated.

On December 11, 1962, he was still doing very well (Dr. Oppé).

The liver has further decreased in size, and on April 26, 1963 , it was reported as being palpable one finger breadth below right costal margin. $\mathrm{He}$ has had measles and has made an uneventful recovery. Haemoglobin was $11.5 \mathrm{~g} . \%$, homovanillic acid in urine was $1 \mathrm{mg} . / 100 \mathrm{ml}$. in 24 hours (Dr. Sandler), i.e. quite normal.

Case 2. Baby P.P., a male, of France, under care of Professor Marcel Lelong and Dr. Odile Schweisguth, was born, full term, on December 27, 1961 ; birth weight 3,400 g. Normal development to 1 month. At that time increase in size of abdomen was observed, as well as irregular weight which had been increasing hitherto.

At 2 months (on March 9, 1962) a hernia was noted. The infant was operated on for right-sided inguinal hernia. A voluminous abdomen persisted, however. At that time liver biopsy was consistent with secondary neuroblastoma. At 3 months child was sent to Paris weighing 4,750 g., malnourished and pale, with enormous abdomen with subumbilical venous anastomoses. There was no digestive trouble and motions were normal. The liver edge nearly reached symphysis pubis. There was lumbar swelling. Abdomen was hard and tender. During first days at hospital liver size increased, and cyanosis and respiratory difficulties suggested an intraabdominal haemorrhage. Red blood cells were $2,750,000$, white blood cells 15,700 with normal differential count; bone marrow, normal; I.V.P. showed downward displacement of left kidney and elongation of calyces. V.M.A. level in urine was $9.6 \mathrm{mg} . / 24$ hours (169.3 $\mu \mathrm{g} . / \mathrm{mg}$. of creatinine). The homovanillic acid was $289 \cdot 2 \mu \mathrm{g} . / \mathrm{mg}$. creatinine (Dr. Kaser, Bern).

On oxygen therapy and digitalis, respiratory troubles regressed within a few days.

From March 31, 1962, he was given $1 \mathrm{mg}$. vitamin $\mathbf{B}_{12}$ i.m. on alternate days. In addition he received three blood transfusions on April 2, 3 and 6.

During first weeks of treatment there was no alteration in abdominal size and infant remained very thin and did not gain weight, but general condition was improved. He did not appear tired any longer; he breathed more calmly and smiled.

At the end of the first month's treatment there was noted regression in the size of the hepatic tumour. At the end of the second month the child was looking better in colour and more mature. In particular, the excretion of vanillic and homovanillic acid decreased rapidly (Table).

TABLE

\begin{tabular}{|c|c|c|c|}
\hline 1962 & V.M.A./day & $\begin{array}{c}\text { V.M.A./ } / \mu g . / m g . \\
\text { Creatinine }\end{array}$ & $\underset{\text { Creatinine }}{\text { H.V.A. } / \mu g . / m g .}$ \\
\hline $\begin{array}{l}\text { April } 17 \\
\text { April } 28 \\
\text { May } 8 \\
\text { May } 27\end{array}$ & $\begin{array}{l}9 \cdot 6 \\
4 \cdot 6 \\
3 \\
3 \cdot 2\end{array}$ & $\begin{array}{r}169 \cdot 3 \\
84 \cdot 4 \\
59 \cdot 1 \\
77 \cdot 5\end{array}$ & $\begin{array}{r}289 \cdot 2 \\
102 \cdot 8 \\
101 \cdot 3 \\
95 \cdot 4\end{array}$ \\
\hline
\end{tabular}

At the age of $6 \frac{1}{2}$ months, on July 18 , the infant was returned to his parents, much improved and continuing treatment with vitamin $B_{12}$ at home. At the age of 10 months, in October 1962, he was seen again, weighing $8,200 \mathrm{~g}$. and looking a well baby. Liver edge was $1.5 \mathrm{~cm}$. below costal margin. There was no lumbar swelling; I.V.P., various haematological and liver function tests, skeletal radiographs, and excretion of vanillic and homovanillic acid were all normal: V.M.A. $15 \mathrm{mg}$. per day $(17 \cdot 3 \mu \mathrm{g} . / \mathrm{mg}$. creatinine); H.V.A. $25 \cdot 6 \mu \mathrm{g} . / \mathrm{mg}$. creatinine (normal range).

The infant was again returned to his family. Vitamin $B_{12}$ was continued at $1 \mathrm{mg}$. on alternate days.

In January 1963, the news was excellent: Philippe, at 1 year of age, had started his tenth month of treatment.

Case 3. P.M., a female infant born April 7, 1962, full-term, after normal pregnancy, weighing $6 \mathrm{lb}$. $6 \frac{1}{2} \mathrm{oz}$. $(2,905$ g.), was under the clinical care of Dr. Norman Clark of Aberdeen; she was a first child.

She had abdominal enlargement from birth, and was referred to the Royal Aberdeen Hospital for Sick Children at 3 weeks, because of enormous abdominal swelling. The liver was firm, smooth and hard and the edge stretched across lower abdomen between iliac crests. Pyelography showed good excretion from both kidneys with some downwards displacement of left. Films of skeleton showed no abnormality. Open biopsy of liver on May 4, showed it was infiltrated throughout with neuroblastoma.

She was started on vitamin $\mathbf{B}_{12}, 1 \mathrm{mg}$. i.m., every second day on May 7, and this dosage has been continued since (one year now). Her abdomen at first continued to enlarge, oedema of legs became gross and it was obvious she was developing an inferior vena cava block.

Radiotherapy was therefore started on May 17 and she was transfused with $120 \mathrm{ml}$. blood. Total dosage of 1,000 rad was given till June 18, with gradual disappearance of oedema of lower half of body and some recession of liver edge which, however, remained well below umbilicus.

Estimation of V.M.A. output on June 1 was $0.56 \mathrm{mg} . /$ 24 hours, and on June $22,0.48 \mathrm{mg}$./24 hours. 
She was discharged home on June 23 weighing 9 lb. $12 \mathrm{oz}$. $(4,422 \mathrm{~g}$.). The family have moved to Fife and she is being followed up by Dr. Mark Fraser in Kirkcaldy. A report on October 26, 1962, shows liver is now 1 in. $(2.54 \mathrm{~cm}$.) above umbilicus and her spleen $\frac{1}{2}$ in. $(1 \cdot 27 \mathrm{~cm}$.) below costal margin. In November 1962, a 24-hour specimen of urine contained $0.42 \mu \mathrm{g}$. V.M.A. $/ 100 \mathrm{ml}$.

She was last seen on April 1, 1963. She has continued to make astonishing progress. She weighed nearly $28 \mathrm{lb}$. $(12 \cdot 7 \mathrm{~kg}$.) and was a bright and happy infant with no obvious abdominal swelling. Her liver edge was one to two fingers below the costal margin; otherwise she seemed normal.

Lung fields were clear, and there was no evidence of calcification on abdominal $\mathrm{x}$-ray examination.

Case 4. Baby K.S. is a male infant under the care of Dr. Mary Wilmers at the Belgrave Hospital for Children. Born December 8, 1956; admitted to hospital on June 12, 1958, aged 18 months. Five weeks previously his mother noticed general loss of weight and reluctance to walk; he was very fretful. Development normal, and he walked at 13 months. There was lower dorsal kyphosis and he was reluctant to extend his spine. Reflexes were present and equal, except that knee jerks were slightly impaired.

One day after admission there was indefinite swelling over lower dorsal spine with kyphotic areas and neck stiffness. Lumbar puncture was merely bloodstained but otherwise normal. He was transferred to the Maudsley Hospital. I.V.P. showed downward displacement of left kidney and left hydronephrosis. Myelogram showed complete block at lower border of $\mathrm{T} 12$, and $\mathrm{X}$-ray changes were suggestive of extradural tumour. Biopsy revealed neuroblastoma.

Treatment with vitamin $\mathbf{B}_{12}$ was commenced-1 $\mathrm{mg}$. i.m. on alternate days. He has made very good progress. In January 1959, at 2 years and 2 months, he weighed $30 \mathrm{lb} .12 \mathrm{oz}$. (14 kg.) and was running around and cheerful. There were no abnormal physical signs and no neurological deficit. On April 28, 1960, he was extremely well with no neurological abnormalities. He was continued on vitamin $\mathbf{B}_{12}$ for three years till June 1961. At that time I.V.P. was quite normal. Some calcification was visible at the level of T12.

Case 5. Baby B.W., a male born in May 1958-under the clinical care of Professor J. K. Martin of Edmonton, Alberta, Canada.

First seen by family doctor on September 26, 1958 (aged 4 months), who had removed several small subcutaneous nodules. Histological examination of these was characteristic of metastatic neuroblastoma. On admission to hospital nothing was found on physical examination apart from one or two minute nodules. Palpation of the abdomen was negative. I.V.P. failed. Chest radiograph was normal. There were no metastases on examination of long bones. Bone marrow taken from tibia, however, showed metastatic tumour cells consistent with neuroblastoma. He was started on vitamin $\mathbf{B}_{12}, 1 \mathrm{mg}$. i.m., on alternate days since second week of October.

Re-examination showed that two nodules on back had disappeared, but a new nodule below navel was discovered that had not previously been felt. He was well and gained in weight. Repeat bone marrow examination again revealed abnormal cell changes suspicious of neuroblastoma. By October 1960, he had completed a twoyear course of vitamin $B_{12}$. He had remained very well, and his growth and development had been normal. The skin nodules had all disappeared.

When last seen in June 1962, a complete physical examination was negative. Urine for V.M.A. test was normal in September 1961, as was bone marrow.

\section{Summary of These Five Cases}

These five cases included four infants (two newborn, one aged 3 months and one aged 4 months) as well as one baby aged 18 months. Three cases were instances of Pepper's syndrome. All but one of these five cases were treated with vitamin $B_{12}$ only; the one exception had 1,000 rad as well. They all responded extremely well to therapy. One case of Pepper's syndrome has been followed for one year, one case for one year and four months, one case for one year and two months, one case for five years and one case for four years and seven months. The two cases other than those of Pepper's syndrome were one instance of extradural neuroblastoma with spinal block, now perfectly well after five years, and one case of multiple subcutaneous neuroblastoma nodules, well after four years and seven months. The only case treated by irradiation (as well as vitamin $\mathbf{B}_{12}$ ) was an instance of Pepper's syndrome, now well after one year and two months.

It is interesting to note that two of the cases of Pepper's syndrome who had been treated with vitamin $\mathbf{B}_{12}$ only, showed gradual return to normal urinary V.M.A. excretion pari passu with clinical improvement.

This miscellaneous series has been recorded for it contains, in addition to the relatively small purely vitamin $B_{12}$-treated children from this hospital, another four such examples. The serial V.M.A. estimations leading to normal levels in two instances are also worthy of note.

\section{Experimental Studies}

Dr. Carolyn Rigby and the author have published the results of experimental studies on the relation between vitamin $\mathrm{B}_{12}$ and two animal tumour systems.

The mouse $\mathrm{C} 1300$ tumour and the P.W.A. tumour in rats have been treated and controlled with massive daily doses of vitamin $B_{12}$ respectively for three and one and a half years. About $25 \%$ regression of tumour size was obtained in the mouse tumour while the fibrosarcoma of the rat did not show any regressive effects.

Biological studies showed that the mouse tumour, in contrast to the rat tumour, showed considerable uptake of vitamin $\mathbf{B}_{12}$, comparable to the liver (the main storage organ), and similar results were obtained when radioactive $\mathrm{Co}^{58}$ vitamin $\mathrm{B}_{12}$ was used. Thus it seems that uptake of vitamin $B_{12}$ by the tumour is associated with its regression. 
The author wishes to thank the British Empire Cancer Campaign for their generous support for this work.

It is a pleasant duty to acknowledge the considerable help in this investigation by the members of the Tumour Committee of The Hospital for Sick Children, Mr. G. H. Macnab, Professor Alan A. Moncrieff and Professor A. W. Wilkinson.

I also wish to thank all those members of the Medical and Surgical Consultant Staff who had the care of the various cases included here.

Moreover, I am grateful for permission to quote their cases to Dr. T. Oppé, of St. Mary's Hospital, London, Professor Marcel Lelong and Dr. Odile Schweisguth, of Paris, Dr. Mary Wilmers, of The Belgrave Hospital for Children, Dr. Norman S. Clark, of the Royal Aberdeen Hospital for Sick Children, and Professor J. K. Martin, of Edmonton, Alberta, Canada.

Finally, I would like to acknowledge the considerable help of Miss E. Joyce, my secretary, for her assistance with this paper.

\section{BIBLIOGRAPHY}

Bodian, M. (1955). Cancer in children. Med. Press, 234, 350. - (1959). Neuroblastoma Pediat. Clin. N Amer., 6, 449.

British Empire Cancer Campaign (1951). A clinico-pathological study of tumours of the sympathetic nervous system in childhood, study of tumours of the sympathetic ner

p. 160. 28th Annual Report, 1950.

(1954). Preliminary observations on the treatment of neuroblastoma with vitamin B12, p. 174. 31st Annual Report, 1953.
(1955). Neuroblastoma. A general review, p. $195.32 \mathrm{nd}$ Annual Report, 1954.

(1956). Neuroblastoma and vitamin B12 therapy, p. 186. 33rd Annual Report, 1955.

(1957). The treatment of neuroblastoma with vitamin B12, p. 213. 34th Annual Report, 1956

p. 213. 34th Annual Report, 1956. p. 227. 35th Annual Report, 1957. Part II. The Scientific p. 227.

(1959). The treatment of neuroblastoma with vitamin B12, p. 274. 36th Annual Report, 1958. Part II. The Scientific Report.

- (1960). The treatment of neuroblastoma with vitamin Bl2. Experimental work related to the biology of vitamin B12, p. 285. 37th Annual Report, 1959. Part II. The Scientific Report. (1961) The treatment of neuroblastoma with vitamin B12. Experimental work related to the biology of vitamin B12, p. 352. 38perimental work related to the biology of vitamin BI2, p. 352 . 38th Annual Report, 1960 . Part II. The Scientific Report. (1962). The treatment of neuroblastoma with vitamin B12. Experimental work related to the biology of vitamin B12, p. 321 39th Annual Report, 1961. Part II. The Scientific Report. Busfield, P. I. (1958). Neurc

Farber, S., Toch, R., Sears, E. M. and Pinkel, D. (1956). Advances in chemotherapy of cancer in man. Advanc. Cancer Res., 4, 1.

Koop C. E. Kiesewetter, W. B. and Horn, R. C. (1955). Neuroblastoma in childhood. Survival after major surgical insult to blastoma in childhood. Surviva
the tumor. Surgery, 38, 272 .

Phillips, R. (1953). Neuroblastoma. Hunterian Lecture. Ann. roy. Coll. Surg. Engl., 12, 29.

Rigby, C. C. and Bodian, M. (1963). Experimental study of the relationship between vitamin $B 12$ and two animal tumour systems. Brit. J. Cancer, 17, 90.

Sutow, W. W. (1958) Prognosis in neuroblastoma of childhood. A.M.A. J. Dis. Child., 96, 299.

Wittenborg, M. H. (1950). Roentgen therapy in neuroblastoma. Radiology, 54, 679. 